\title{
In-cylinder thermochemical fuel reforming (TFR) in a spark-ignition natural
}

\section{gas engine}

Lei Zhu*a, Zhuoyao Hea, Zhen Xu a, Xingcai Lu a, Junhua Fang a, Wugao Zhang a , Zhen Huang a

${ }^{a}$ Key Laboratory for Power Machinery and Engineering of M.O.E, Shanghai Jiao Tong University, Shanghai, P.R. China

Corresponding author: Lei Zhu

Mailing address: School of Mechanical Engineering, Shanghai Jiao Tong University, Shanghai, P.R.

China.

Email: tonyzhulei@gmail.com

\section{Word equivalent lengths (Method 1):}

\section{Total: $\mathbf{5 8 8 1 . 2 8}$ words}

- Main text: 3674 words (MS word processor utility)

- Equations: total 114 words $=(\# 15+\# 0) \times(7.6$ words/line $) \times(\#$ columns $)=114$ words

- References: total 367.08 words $=[(\# 19+2) \times(2.3$ lines $/$ reference $) \times(7.6$ words/line $)]=367.08$ words

- Tables: total 152 words $=(\#$ text lines +2 lines $) \times(7.6$ words/line $) \times$ (\#columns)

Table 1: $11 \times 7.6=83.6$ words Table 2: 9x7.6=68.4 words

- Figures: total 1567.2 words $=($ figure height in $\mathrm{mm}+10 \mathrm{~mm}) \times(2.2$ words $/ \mathrm{mm}) \times$ (\#columns $)+($ \#words in caption) Figure 1: $118.8+4=122.8$ words $\quad(67 \mathrm{~mm} \times 44 \mathrm{~mm})$ Figure 2: $127.6+10=137.6$ words $\quad(67 \mathrm{~mm} \times 48 \mathrm{~mm})$ Figure 3: $125.4+11=136.4$ words $\quad(67 \mathrm{~mm} \times 47 \mathrm{~mm})$

Figure 4: $220+12=232$ words $(67 \mathrm{~mm} \times 90 \mathrm{~mm})$

Figure 5: $206.8+16=222.8$ words $\quad(144 \mathrm{~mm} \times 37 \mathrm{~mm})$

Figure 6: $127.6+22=149.6$ words $\quad(67 \mathrm{~mm} \times 48 \mathrm{~mm})$

Figure $7: 125.4+18=143.4$ words $\quad(67 \mathrm{~mm} \times 47 \mathrm{~mm})$

Figure 8: $127.6+13=140.6$ words $\quad(67 \mathrm{~mm} \times 48 \mathrm{~mm})$

Figure 9: $127.6+17=144.6$ words $\quad(67 \mathrm{~mm} \times 48 \mathrm{~mm})$

Figure 10: $125.4+19=144.4$ words $\quad(67 \mathrm{~mm} \times 47 \mathrm{~mm})$ 


\section{Abstract}

This experimental study demonstrates the potential to apply the thermochemical fuel reforming (TFR) concept to simultaneously reduce emissions and improve brake specific fuel consumption in a spark-ignition natural gas engine. $\mathrm{CH}_{4}, \mathrm{H}_{2}$ and $\mathrm{CO}$ are the major components of TFR exhaust gas over a range of rich equivalence ratios. A numerical analysis is conducted to illustrate the chemical reaction pathways for $\mathrm{H}_{2}$ and $\mathrm{CO}$ formation, which occurs in the cylinder during the TFR process. The main reaction pathways for $\mathrm{H}_{2}$ and $\mathrm{CO}$ formation under 3 modeling conditions (20, 50 and $80 \%$ fuel consumed) are different from each other. According to the experimental analysis, thermochemical fuel reforming gas improves combustion performance and accelerates the burn rate in every phase of the natural gas engine. Combustion stability, brake thermal efficiency, brake specific fuel consumption (BSFC), brake specific hydrocarbon (BSHC) and brake specific carbon monoxide (BSCO) emissions can also be improved by TFR. The brake specific oxides of nitrogen (BSNOx) emissions for natural gas engines, combined with a TFR system, are still lower than those of an original natural gas engine in the same operation mode. Thermochemical fuel reforming has been shown to be effective in simultaneously reducing emissions and improving thermal efficiency for a spark-ignition natural gas engine. Furthermore, a 1.2 equivalence ratio for cylinder 4 (TFR cylinder) can be recommended in future research on TFR optimization, based on BSFC and combustion stability.

Keywords: Thermochemical fuel reforming; Spark-ignition; Natural gas; EGR; Hydrogen; 


\section{Introduction}

Given growing concerns about energy security and future oil supplies, natural gas has the potential for applications in transportation because of its reduced environmental burden and lower $\mathrm{CO}_{2}$ emissions relative to conventional fuels, applicability to conventional diesel and gasoline engines and increased anti-knock characteristic resulting from its high octane number (120-130) [1-2]. However, natural gas's low flame velocity and narrow flammability limits [3] result in natural gas spark-ignition engines suffering several disadvantages; specifically, large cycle-to-cycle variations, poor lean-burn capability and poor exhaust gas recirculation (EGR) tolerance, all of which decrease the engine power output and thermal efficiency while increasing fuel consumption. Lean-burn natural gas engines are a common way of achieving high thermal efficiency due to the lower heat and pumping losses and moderately low NOx emissions, while resulting in an increase in engine-out $\mathrm{CO}$ and $\mathrm{HC}$ emissions due to slower flame initiation and propagation. Moreover, due to the poor lean-burn capability of natural gas, many problems still exist with lean-burn natural gas engines, such as flame quenching, partial burn, combustion instabilities and methane slip [4-5]. When required to meet stringent emission regulations, lean-burn combustion cannot reduce NOx emissions to the regulatory requirement (such as Euro VI), which need a rather complex deNOx system such as the selective catalytic reduction (SCR) method to confirm additional NOx reduction.

Given the disadvantages of lean-burn natural gas engines, a stoichiometric natural gas engine equipped with EGR and a 3-way catalyst is considered as a strategy to meet stringent emission regulations [5]. It has been demonstrated that NOx emissions can be reduced by $99.9 \%$ and HC emissions by $90-97 \%$ by operating at a stoichiometric equivalence ratio combined with EGR and a three-way catalyst [6], but the thermal efficiency drops compared with a lean-burn high efficiency 
engine, due to its high flame temperature and heat loss. Moreover, the introduction of EGR gas coincidentally decreases flame propagation velocity due to a low burning velocity, resulting in the reduction of brake thermal efficiency and combustion stability. However, an EGR system can also reduce the exhaust temperature and thermal load of the turbocharger. Thus, it is important to develop innovative methods to achieve a high thermal efficiency and low specific fuel consumption of stoichiometric natural gas engines.

In comparison to natural gas, hydrogen has broader flammability limits, a higher flame velocity and a smaller quenching distance, allowing it to burn in more diluted conditions, which makes it a good supplement for natural gas [7]. In previous studies, the $\mathrm{H}_{2}$ and natural gas were premixed in a bottle or mixer before the experiment and supplied using the same fuel system. Hydrogen can be supplied with on-board $\mathrm{H}_{2}$ production by exhaust gas fuel reforming using a fuel reforming catalyst device [9]. However, there is an additional cost for the fuel reforming reactor, and the engine system layout must be changed. Moreover, the catalyst of a fuel reforming reactor is more easily poisoned by the sulfur content in natural gas. Another new way to produce $\mathrm{H}_{2}$ on board is thermochemical fuel reforming with fuel rich combustion. $\mathrm{H}_{2}$ and $\mathrm{CO}$ production has been proved using super-adiabatic combustion of ultra-rich methane-air mixtures [10]. For the range of equivalence ratios (2 to 8 ) and reactor pressures (1, 3, 5 atm) investigated, the maximum experimental conversion of $\mathrm{CH}_{4}$ to $\mathrm{H}_{2}(65 \%)$ and $\mathrm{CO}(75 \%)$ were observed. This concept has been shown in dedicated EGR systems of a gasoline engine [11]. The combination of EGR and reformed fuel offers improved anti-knock characteristics and improved EGR tolerance, which could allow an increase in the compression ratio and dilution ratio, resulting in up to a $10 \%$ fuel consumption reduction. This concept has also been used in the negative valve overlap reforming of gasoline engines to control the combustion phasing in homogeneous charge compression ignition (HCCI) and other forms of advanced combustion [12]. However, there have been few studies on the TFR of 
natural gas and its application in natural gas spark-ignition engines. It has been noted that if this concept were to work well in a natural gas engine, then the fuel properties of the reforming gas from fuel-rich thermochemistry could be changed conveniently and flexibly on board.

This study is composed of two sections. First, a numerical analysis is used to illustrate the chemical reaction pathways for $\mathrm{H}_{2}$ and $\mathrm{CO}$ formation, which occurs in the cylinder during the thermochemical fuel reforming (TFR) process. Second, this study experimentally demonstrates the potential to apply the in-cylinder thermochemical fuel reforming concept to simultaneously reduce emissions and improve thermal efficiency in a spark-ignition natural gas engine.

\section{Experimental setup}

A four-cylinder spark-ignition natural gas engine coupled with an eddy-current dynamometer was used in this study. The engine specifications are presented in Table 1 and the natural gas

composition are given in Table 2. The compressed natural gas (CNG) was supplied to the six natural gas injectors installed in the intake manifold via a pressure reducer from the CNG bottles. The injection parameters such as duration were set by an electronic unit. The engine operated at an 11:1 compression ratio. The tests were conducted at a steady engine speed of $1500 \mathrm{r} / \mathrm{min}$ and at engine loads of 226 and $323 \mathrm{Nm}$, corresponding to $0.54 \mathrm{MPa}$ and $0.77 \mathrm{MPa}$ BMEP (brake mean effective pressure) respectively.

A shaft encoder, a Kistler piezoelectric pressure transducer (6118B) and a Kistler charge amplifier (5115) were used to transmit the crank angle and in-cylinder pressure to the D2T combustion analyzer (Evolution 3). The piezoelectric transducer was mounted in position of the spark plug. The cylinder pressure was recorded every 0.5 CA. The CO, carbon dioxide, oxygen, unburned HC and NOx were analyzed by California Analytical Instruments (CAI). The CO emissions were 
measured using a non-dispersive infra-red analyzer (NIDR CAI602P). The total HC and NOx emissions were measured using a heated flame ionization detector (HFID CAI600) and a heat chemiluminescent analyzer (HCLD CAI600), respectively. A self-developed procedure with Labview Software was used for emission data acquisition with a data acquisition card. The composition of TFR gas was detected with gas chromatography/thermal conductivity detector (GC/TCD) and gas chromatography/flame ionization detector (GC/FID) off-line measurement. The standard errors were 3.2\%,3.6\%, 2.9\% and 5.2\% for in-cylinder pressure, HC, NOx and CO respectively. Student's T-test was used to analyze whether the differences between the results obtained from different conditions were statistically significant at the 95\% confidence level.

\section{Concept of in-cylinder TFR in a spark-ignition natural gas engine}

The major modification to the engine used in this study was the separation and reconnection of the exhaust pipe of cylinder 4 from the main exhaust manifold to the intake manifold passing trough an EGR cooler. In all of the conditions, 25\% EGR could be realized and maintained after establishing this direct connection without any EGR valve. Moreover, an additional CNG common rail and two injectors were used to inject the CNG near the intake valve of cylinder 4, with another electronic unit controlling the injection timing and duration. After combining these modifications, the equivalence ratio in cylinder 4 (TFR cylinder) could be changed independent of any other cylinders. To maintain a stable equivalence ratio in cylinder 4, the additional CNG injection system was calibrated before the experiment. The equivalence ratio of cylinder 4 could be changed from 1.0 to 1.4 with different $C N G$ injection durations in the intake manifold to realize rich combustion. The global equivalence ratio in the other three cylinders was maintained at 1 . The TFR exhaust gas in cylinder 4 was supplied to the intake manifold for all cylinders. The components formed by TFR 
with higher reactivity could be mixed with inlet air and natural gas, and drawn into all of the cylinders as the piston moved down. Thus, after modification, there are two typical features for in-cylinder TFR system. First, it can provide 20\% cooler EGR to control the formation of NOx emission. Second, it can provide TFR gas to be ignited together with CNG to improve the flame speed. The experimental setup is shown in Figure 1.

\section{Numerical analysis tool}

To calculate the $\mathrm{H}_{2}$ and $\mathrm{CO}$ formation in the cylinder with thermochemical reactions, the Premixed Laminar Flame-Speed Calculation Model in CHEMKIN-PRO was used. Methane was selected as the work fuel, with a 4:1 atomic ratio of hydrogen to carbon. It was expected to get much more $\mathrm{H} 2$ and CO by combustion in the TFR cylinder due to rich and incomplete combustion. GRI-Mech Version 3.0 was chosen as the reaction scheme for the methane, which contained 53 chemical species and 325 elementary reactions to illustrate the reaction pathways for $\mathrm{H}_{2}$ and $\mathrm{CO}$ formation by thermochemical fuel reforming.

\section{Discussion and results}

\subsection{Combustion process in cylinder 4 (TFR cylinder)}

In-cylinder pressure of TFR cylinder was measured with Kistler piezoelectric transducer. Figure 2 shows the combustion process in cylinder 4, which produced TFR gas. According to the figure, the

combustion process in cylinder 4 deteriorated as the equivalence ratio increased, indicating incomplete combustion in the TFR cylinder. The composition of the TFR exhaust gas was sampled and measured with GC-FID and GC-TCD offline. As Figure 3 shows, the concentrations of all of the 
species increased with the equivalence ratio in cylinder 4 . The incomplete combustion occurred with TFR, leading to the formation of $\mathrm{H}_{2}$ and $\mathrm{CO} \mathrm{CH}_{4}, \mathrm{H}_{2}$ and $\mathrm{CO}$ were the major components in the TFR exhaust gas over a range of rich equivalence ratios. The other components such as $\mathrm{C}_{2} \mathrm{H}_{6}, \mathrm{C}_{2} \mathrm{H}_{4}$ and $\mathrm{C}_{3} \mathrm{H}_{8}$ might have stemmed from the natural gas, according to Table 2 .

\subsection{Prediction of hydrogen and CO}

In Figure 4, the experimental data for $\mathrm{H}_{2}$ and $\mathrm{CO}$ formation in the TFR cylinder is compared with applicable models using the experiment's temperature and pressure phased in spark timing as the boundary condition. The trend of simulation data agree well with the experimental data, with an equivalence ratio for the TFR cylinder from 1.0 to 1.2 . The differences among the chemical mechanisms became increasingly obvious as the TFR equivalence ratio rose from 1.2 to 1.4 . A possible explanation for this difference is the unstable condition for a natural gas engine with TFR, when the equivalence ratio of the TFR cylinder exceeds 1.2 , such as in-complete in-cylinder flame propagation and misfire in TFR cylinder. This is discussed in detail in next section. The model and mechanisms did not accurately capture the whole trend during the shift from 1.0 to 1.4 for the TFR equivalence ratio, but they simulated well near 1.2. Thus, a 1.2 TFR equivalence ratio was selected to analyze the reaction pathway for $\mathrm{H}_{2}$ and $\mathrm{CO}$ formation.

\subsection{Reaction pathway analysis for $\mathrm{H} 2$ and CO formation in a TFR cylinder}

The rate of production analysis was conducted using a GRI-Mech V3.0 mechanism to identify the reaction pathways that were important for $\mathrm{H}_{2}$ and $\mathrm{CO}$ formation during TFR. The reaction path analysis was performed for three conditions-20, 50 and $80 \%$ fuel consumption-based on the PREMIX model. Figure 5 shows the main reaction paths for $\mathrm{H}_{2}$ and $\mathrm{CO}$ formation in the three 
modeling conditions. The percentages listed in the figures quantify the specific reaction pathways relative to the overall consumption of the individual species.

In the beginning of the reaction, under $20 \%$ fuel consumption, the reaction path diagram did not contain the $\mathrm{H}_{2}$ formation. There was only one main reaction pathway for CO formation. H-atom abstraction via the $\mathrm{OH}$ radical was the initial dominant pathway for $\mathrm{CH}_{4}$ consumption, as seen in R1.

$\mathrm{OH}+\mathrm{CH}_{4}<=>\mathrm{CH}_{3}+\mathrm{H} 2 \mathrm{O}$

Virtually most of the $\mathrm{CH}_{3}$ radical reacted with $\mathrm{HO}_{2}$ to form $\mathrm{CH}_{3} \mathrm{O}(\mathrm{R} 2)$. The $\mathrm{CH}_{3} \mathrm{O}$ reacted with the third body (+M) (R3) and with oxygen to form $\mathrm{CH}_{2} \mathrm{O}(\mathrm{R} 4) . \mathrm{CH}_{2} \mathrm{O}$ mainly decomposed by $\mathrm{R} 5$ via $\mathrm{OH}$. Eventually, most of the $\mathrm{CH}_{2} \mathrm{O}$ reacted with $\mathrm{OH}$ to produce $\mathrm{HCO}$. And then, after the five reactions (R1-R5) convert $\mathrm{CH}_{4}$ into $\mathrm{HCO}, \mathrm{HCO}$ was mostly consumed by oxygen to yield $\mathrm{CO}$ (R6).

$\mathrm{HO}_{2}+\mathrm{CH}_{3}<=>\mathrm{OH}+\mathrm{CH}_{3} \mathrm{O}$

$\mathrm{CH}_{3} \mathrm{O}(+\mathrm{M})<=>\mathrm{H}+\mathrm{CH}_{2} \mathrm{O}(+\mathrm{M})$

$\mathrm{CH}_{3} \mathrm{O}+\mathrm{O} 2<=>\mathrm{HO}_{2}+\mathrm{CH}_{2} \mathrm{O}$

$\mathrm{OH}+\mathrm{CH}_{2} \mathrm{O}<=>\mathrm{HCO}+\mathrm{H}_{2} \mathrm{O}$

$\mathrm{HCO}+\mathrm{O}_{2}<=>\mathrm{HO}_{2}+\mathrm{CO}$

At $50 \%$ fuel consumption, $\mathrm{CH}_{4}$ was consumed in three pathways: $\mathrm{CH}_{4}$ reacting with small radicals such as $\mathrm{OH}, \mathrm{H}$ and $\mathrm{O}$ to produce $\mathrm{CH}_{3}$ with $\mathrm{H}$-abstracted. The most methyl was generated not only by R1, but also through $\mathrm{H}$-abstraction from methane via $\mathrm{H}$ radical (R7) during methane decomposition. All $\mathrm{CH}_{3}$ radicals were consumed with two routes, reacting with $\mathrm{HO}_{2}$ to form $\mathrm{CH}_{3} \mathrm{O}$ (R2) and reacting with the third body (+M) to form $\mathrm{C}_{2} \mathrm{H}_{6}$ (R8). Most of $\mathrm{CH}_{3} \mathrm{O}$ reacted with the third body (+M) to form $\mathrm{CH}_{2} \mathrm{O}(\mathrm{R} 3)$.

$\mathrm{H}+\mathrm{CH}_{4}<=>\mathrm{CH}_{3}+\mathrm{H}_{2}$

$2 \mathrm{CH}_{3}(+\mathrm{M})<=>\mathrm{C}_{2} \mathrm{H}_{6}(+\mathrm{M})$ 
While the routes of $\mathrm{CH}_{2} \mathrm{O}$ consumption were different from the location of $20 \%$ fuel consumed. Most of $\mathrm{CH}_{2} \mathrm{O}$ reacted with $\mathrm{H}$ (R9), $\mathrm{OH}$ (R5) and $\mathrm{CH}_{3}$ (R10) to produce HCO. And then, $\mathrm{CO}$ could be formed through R6, R11 and R12 by HCO reacting with oxygen, third body (+M), and $\mathrm{H}_{2} \mathrm{O}$.

$\mathrm{H}+\mathrm{CH}_{2} \mathrm{O}<=>\mathrm{HCO}+\mathrm{H}_{2}$

$\mathrm{CH} 3+\mathrm{CH}_{2} \mathrm{O}<=>\mathrm{HCO}+\mathrm{CH}_{4}$

$\mathrm{HCO}+\mathrm{M}<=>\mathrm{H}+\mathrm{CO}+\mathrm{M}$

$\mathrm{HCO}+\mathrm{H}_{2} \mathrm{O}<=>\mathrm{H}+\mathrm{CO}+\mathrm{H}_{2} \mathrm{O}$

For hydrogen, there were three major routes for $\mathrm{H}_{2}$ formation: through $\mathrm{H}$ abstraction via $\mathrm{CH}_{4}$, $\mathrm{CH}_{2} \mathrm{O}$ and $\mathrm{C}_{2} \mathrm{H}_{6}$, according to R7, R13 and R14.

$\mathrm{H}+\mathrm{CH}_{2} \mathrm{O}<=>\mathrm{HCO}+\mathrm{H}_{2}$

$\mathrm{H}+\mathrm{C}_{2} \mathrm{H}_{6}<=>\mathrm{C}_{2} \mathrm{H}_{5}+\mathrm{H}_{2}$

Once $80 \%$ of the fuel had been consumed, most of the $\mathrm{CO}$ was generated not by $\mathrm{HCO}$ reacting with $\mathrm{O}_{2}$ (R6), but through $\mathrm{H}$-abstraction from $\mathrm{HCO}$ via $\mathrm{H}_{2} \mathrm{O}$ (R12) and +M (R11). Moreover, part of the $\mathrm{CO}$ could also have been formed through $\mathrm{R} 15$ by $\mathrm{CH}_{3}$ reacting with $\mathrm{O}$ radicals.

$\mathrm{O}+\mathrm{CH}_{3}<=>\mathrm{H}+\mathrm{H}_{2}+\mathrm{CO}$

For $\mathrm{H}_{2}$ formation, the three major routes were $\mathrm{H}$-abstraction from $\mathrm{CH}_{4}$ and $\mathrm{C}_{2} \mathrm{H}_{6}$ via $\mathrm{H}$ radical by $\mathrm{R} 7$ and $\mathrm{R} 14$, and $\mathrm{CH}_{3}$ reacting with 0 radical to form $\mathrm{H}_{2}$ (R15), when $80 \%$ fuel had been consumed. The radical pool ( $\mathrm{H}$ radical) clearly played a key role in $\mathrm{H}_{2}$ formation in every stage of fuel consumption, because hydrogen is mainly produced when the hydrocarbon reacts with $\mathrm{H}$ radicals [13]. According to the pathways of three cases, $\mathrm{H}_{2}$ could not be formed in the first stage of fuel conversion, as shown in the case of $20 \%$ fuel consumption. $\mathrm{CO}$ and $\mathrm{H}_{2}$ can be formed simultaneously in the case of 50\% and $80 \%$ fuel consumption, indicating that the formation of $\mathrm{H}_{2}$ and $\mathrm{CO}$ is more pronounced at the place where is closer to the post flame region in the flame layer. 


\subsection{Combustion analysis of natural gas engine with TFR system}

The effect of the equivalence ratio in cylinder 4 on the in-cylinder pressure and the heat release rate, measured at $1500 \mathrm{rpm}$ and $0.54 \mathrm{MPa}$, respectively, is depicted in Figure 6. The maximum in-cylinder pressure and the heat release rate increased and moved toward the TDC with the equivalence ratio in the TFR cylinder, which means that the TFR gas helped improve the burn rate in the natural gas engine. Figure 7 shows the improvements in the burn rates and reduction in mass fraction burned (MFB) duration of cylinders 1-3 as a function of cylinder 4's equivalence ratio. Every burn phase was improved by the addition of TFR gas. The largest improvement was at the end of the combustion stage during the $50-95 \%$ mass fraction burn period. Natural gas has a lower combustion flame speed due to the slow reaction of $\mathrm{CH}_{4}+\mathrm{O}$ to $\mathrm{CH}_{3}+\mathrm{OH}$ [7]. The higher concentration of $\mathrm{OH}$ radicals due to the addition of $\mathrm{H}_{2}$ in TFR gas enhanced the removal of the first hydrogen atom from the methane molecule, leading to shorter, faster combustion than that of natural gas $[14,15]$. Moreover, due to the existence of hydrogen in TFR gas, the overall concentration of hydrogen in the air-fuel mixture increased in cylinders 1-3, thus accelerating the chemical reaction of $\mathrm{OH}+\mathrm{H}_{2}->\mathrm{H}+\mathrm{H}_{2} \mathrm{O}$ and further increasing the $\mathrm{H}$ radical's concentration in the flame region. The reaction of $\mathrm{H}+\mathrm{O}_{2}->0+\mathrm{OH}$ improved almost immediately and generated more $\mathrm{O}$ and $\mathrm{OH}$ radicals, which improved the combustion process, as shown in Figure 7. Regarding CO, although its laminar flame speed was lower than that of natural gas, $\mathrm{CO}$ also improved combustion, similar to $\mathrm{H}_{2}$. When $\mathrm{CO}$ burns in wet air (with water vapor) or contains $\mathrm{H}_{2}$ in its mixture, its primary oxidation process is transferred to $\mathrm{OH}+\mathrm{CO}->\mathrm{H}+\mathrm{CO}_{2}$, which can accelerate the combustion process [16].

The effects of the equivalence ratio in cylinder 4 on the $\mathrm{CoV}$ of indicated mean effective pressure (IMEP) of cylinders 1-3 are shown in Figure 8. The engine became unstable at an engine load of 
0.54MPa, with 25\% EGR without any TFR. When the equivalence ratio of cylinder 4 increased from 1.0 to 1.2 , the engine entered a very stable combustion condition. According to Figure 3, $\mathrm{CH}_{4}, \mathrm{H}_{2}$ and $\mathrm{CO}$ were the major components in TFR exhaust gas. After being blended and drawn into the cylinder, $\mathrm{H}_{2}$ enrichment could be realized in the fuel-air mixture. The ignition energy of $\mathrm{H}_{2}$ is only one-fifteenth that of methane at a normal temperature and air pressure [17]. The lower ignition energy and high flame speed of $\mathrm{H}_{2}$ promoted fast and complete combustion, shortened flame development duration and improved flame kernel formation [7], leading to a lower CoV of IMEP. The key factors of flame stability are $\mathrm{H}$ radicals, because of the important chain branching reaction $\mathrm{H}+\mathrm{O}_{2}<=>\mathrm{OH}+\mathrm{O}$ [7]. The additional $\mathrm{H}_{2}$ in TFR gas leads to higher concentrations of $\mathrm{H}, \mathrm{O}$ and $\mathrm{OH}$, which improves the reaction $\mathrm{H}+\mathrm{O}_{2}<=>\mathrm{OH}+\mathrm{O}$, resulting in a lower $\mathrm{CoV}$ of IMEP. After increasing from 1.2 to 1.4 , the $\mathrm{CoV}$ of IMEP exceeded 5\%, indicating an unstable condition, especially at a 0.77MPa engine load.

The potential for improvement in fuel consumption with TFR was also examined in this study. The fuel consumption measured in this study included an additional CNG injection for rich combustion in cylinder 4. As Figure 9 shows, the brake specific fuel consumption (BSFC) decreased as the equivalence ratio for cylinder 4 increased from 1.0 to 1.2, compared with 25\% EGR without in-cylinder fuel reforming. A possible reason is that the combustion process with TFR gas was phased closer to the top dead center, suggesting a faster combustion process that led to higher brake thermal efficiency and lower brake specific fuel consumption. Thus, according to the CoV and BSFC analysis, a 1.2 equivalence ratio for cylinder 4 can be recommended.

\subsection{Emissions characteristics of natural gas engine with TFR system}

Figure 10 shows the effects of TFR on brake specific emissions. BSHC and BSCO decreased as the 
equivalence ratio increased from 1.0 to 1.2. A possible reason for this result is that the higher homogeneity of the fuel/air mixture, the increased stability of combustion, the wide flammability limits and the shorter quenching distance of $\mathrm{H}_{2}$ compared with that of methane allowed the flame to propagate through regions of high dilution in the combustion chamber, suppress misfires and partial burn and contribute to more complete combustion, especially close to the combustion chamber wall [18]. On the other hand, due to the lower $\mathrm{H}_{2}$ ratio in TFR exhaust gas, the fuel mixture in cylinder contain a higher methane mole fraction relative to hydrogen and carbon monoxide, and thus methyl radical chemistry still tends to dominate. During the oxidation of methane, hydroperoxyl radical chemistry (R2) could be improved due to $\mathrm{HO}_{2}$ formation by $\mathrm{H}_{2}$ reacting with $\mathrm{O}$ radical to form $\mathrm{H}$ and $\mathrm{OH}$, and then by $\mathrm{H}$ reacting with oxygen and third body to form $\mathrm{HO}_{2}$ [19]. $\mathrm{H}_{2}$ in combustion chamber could promote reactivity as it produces a lot of $\mathrm{H}$ and $\mathrm{OH}$ radicals, resulting in the improvement of methane oxidation and lower $\mathrm{HC}$ emissions.

The side effect of a fast combustion, lower fuel consumption, high-thermal-efficiency TFR engine was an increase in BSNOx emissions, due to the increase in the peak combustion temperature within the cylinder. The BSNOx emissions for the TFR engine were still lower than those of an original natural gas engine in the same operation mode.

\section{Conclusion}

In this study, numerical and experimental analyses illustrate the chemical reaction pathways for $\mathrm{H}_{2}$ and CO formation that occurs in TFR process, and demonstrate the potential to apply the in-cylinder TFR concept to simultaneously reducing emissions and improving thermal efficiency in a spark-ignition natural gas engine. The major conclusions of the study are as follows.

There is an incomplete and rich combustionoccurring in the TFR cylinder. $\mathrm{CH}_{4}, \mathrm{H}_{2}$ and $\mathrm{CO}$ were the 
major components in the TFR exhaust gas over a range of rich equivalence ratios $(1.0-1.4)$. The main reaction pathways for $\mathrm{H}_{2}$ and $\mathrm{CO}$ formation under the three modeling conditions $(20,50$ and $80 \%$ fuel consumption) were different from each other. At the beginning of oxidation, the reaction path diagram did not contain the $\mathrm{H}_{2}$ formation. There was only one main reaction pathway for $\mathrm{CO}$ formation by $\mathrm{HCO}$ reacting with $\mathrm{O}_{2}$. Under $50 \%$ and $80 \%$ fuel consumption, the major routes for $\mathrm{H}_{2}$ formation were $\mathrm{H}$-abstraction from $\mathrm{CH}_{4}$ and $\mathrm{C}_{2} \mathrm{H}_{6}$ via $\mathrm{H}$ radical. Most of the $\mathrm{CO}$ was generated through $\mathrm{H}$-abstraction from $\mathrm{HCO}$ via $\mathrm{H}_{2} \mathrm{O}$, the third body $(+\mathrm{M})$ and $\mathrm{O}_{2}$. The radical pool (H radical) played a key role in $\mathrm{H}_{2}$ formation in every stage of fuel consumption, because hydrogen is mainly produced when the hydrocarbon reacts with $\mathrm{H}$ radicals.

The TFR gas improved combustion performance and accelerated the burn rate in every phase of the natural gas engine. The CoV of IMEP for the natural gas engine was reduced nearly $60 \%$ by increasing the equivalence ratio of TFR cylinder from 1.0 to 1.2 at engine load of $0.54 \mathrm{MPa}$. Combustion stability, brake thermal efficiency and brake fuel consumption could be improved by TFR. Moreover, BSHC and BSCO decreased $12 \%$ and $8 \%$ as the equivalence ratio of TFR cylinder increased from 1.0 to 1.2. The BSNOx emissions for a natural gas engine combined with a TFR system could be reduced nealy $65 \%$ in comparison to the original natural gas engine in the same operation mode.

Thus, in-cylinder thermochemical fuel reforming was shown to be effective in simultaneously reducing emissions and improving thermal efficiency for a spark-ignition natural gas engine. Furthermore, a 1.2 equivalence ratio for TFR cylinder is recommended in future research on the optimization of TFR, based on BSFC and combustion stability.

\section{Acknowledgements}

The authors would like to thank the National Science Foundation of China (Project No. 51306117; 
51436005), the Ministry of Science and Technology (MOST) of China (Project No. 2012BAD47B04) and the Foundation of Shanghai Jiao Tong University for supporting this research. 


\section{References}

[1] T. Korakiznitis, A.M. Namasivayam, R.J. Crookes, Prog. Energy Combust. Sci. 37 (2011) 89-112.

[2] A. Mariani, B. Morrone, A. Unich, Int. J. Hydrogen Energy 37 (2012) 2644-2654.

[3] S. Rousseau, B. Lemoult, M. Tazerout, Proc. Inst. Mech. Engrs. Part D 213 (1999) 481-489.

[4] T. Kato, K. Saeki, H. Nishide, T. Yamada, JSAE Rev 22 (2001) 365-368.

[5] H.M. Cho, B.Q. He, Energ. Convers. Manage. 48 (2007) 608-618.

[6] P. Einewall, P. Tunestal, B. Johansson, SAE Technical Paper 2005-01-0250.

[7] S.D. Iorio, P. Sementa, B.M. Vaglieco, Int. J. Hydrogen Energy 39 (2014) 9809-9823.

[8] B. Korb, S. Kawauchi, G. Wachtmeister, Fuel 164 (2016) 410-418.

[9] Y. Huang, C.J. Sung, J.A. Eng, Proc. Combust. Inst. 29 (2002) 759-765.

[10] M.K. Drayton, A.V. Saveliev, L.A. Kennedy, A.A. Fridman, Y.E. Li, Proc. Combust. Inst. 27 (1998) 1361-1367.

[11] T. Alger, B. Mangold, SAE Technical Paper 2009-01-0694.

[12] J.P. Szybist, R.R. Steeper, D. Splitter, V.B. Kalaskar, J. Pihl, C. Daw, SAE Technical Paper 2014-01-1188.

[13] H. Watanabe, F. Arai, K. Okazaki, Combust. Flame 160 (2013) 2375-2385.

[14] K. Collier, N. Mulligan, D. Shin, S. Brandon, SAE Technical Paper 2005-01-0235.

[15] R.W. Shefer, Int. J. Hydrogen Energy 28 (2003) 1131-1141.

[16] M. Rightley, F. Williams, Combust. Flame 110 (1997) 285-297.

[17] J. Herzler, C. Naumann, Proc. Combust. Inst. 32 (2009) 213-220.

[18] T. Alger, J. Gingrich, B. Mangold, SAE Technical Paper 2007-01-0475.

[19] N. Donohoe, A. Heufer, W.K. Metcalfe, H.J. Curran, M.L. Davis, O. Mathieu, D. Plichta, A. Morones, E.L. Petersen, F. Guthe, Combust. Flame 161 (2014) 1432-1443. 


\section{Figure captions}

Fig. 1 Experimental system

Fig. 2 In-cylinder pressure of TFR cylinder at 0.54MPa BMEP

Fig. 3 Concentration of gas composition in TFR at 0.54MPa BMEP

Fig. 4 Experimental and computed concentration of $\mathrm{H}_{2}$ and $\mathrm{CO}$ in TFR

Fig. 5 Reaction pathways for $\mathrm{H}_{2}$ and $\mathrm{CO}$ formation during TFR process at 657K, 13.04bar, $\psi=1.2$

Fig. 6 In-cylinder pressure and heat release rate of cylinder 1-3 as a function of TFR cylinder's equivalence ratio at $0.54 \mathrm{MPa} \mathrm{BMEP}$

Fig. 7 Burn duration improvement cylinder 1-3 as a function of TFR cylinder's equivalence ratio at 0.54MPa BMEP

Fig. $8 \mathrm{CoV}_{\text {IMEP }}$ of engine as a function of TFR cylinder's equivalence ratio

Fig. 9 Brake specific fuel consumption of engine as a function of TFR of cylinder's equivalence ratio Fig. 10 Brake specific emissions of engine as a function of TFR of cylinder's equivalence ratio at 0.54MPa BMEP 